\title{
Racismo no Brasil e racismo à brasileira: traços originários
}

\author{
Joilson Santana Marques Junior ${ }^{1}$
}

\begin{abstract}
Resumo
O presente artigo busca traços originários que constroem o chamado racismo à brasileira, entendendo esse como forma sofisticada que responde à concretude das relações raciais brasileiras. Tomando-o como um dos elementos estruturais da sociedade brasileira. Pode-se considerar que há três momentos chave para a concepção do chamado racismo à brasileira estes são: o sistema escravista, o racismo científico em seu modo particular de apropriação pela intelectualidade nacional e a mestiçagem/miscigenação em Gilberto Freyre como premissa do branqueamento. Desse modo, expressões aparentemente surpreendentes de racismo hoje podem ser mais bem compreendidas, à luz das inflexões do próprio racismo enquanto construção sócio-histórica.
\end{abstract}

\section{Palavras-chave \\ Raça; Racismo; Desigualdade;}

\section{Racism in Brazil and Brazilian racism: original traits}

\begin{abstract}
This article looks for original traits that build the so-called racism towards Brazilian women, understanding this as a sophisticated form that responds to the concreteness of Brazilian race relations. Taking it as one of the structural elements of Brazilian society. It can be considered that there are three key moments for the conception of the so-called Brazilian racism, these are: the slave system, scientific racism in its particular mode of appropriation by the national intelligentsia and miscegenation / miscegenation in Gilberto Freyre as a premise of whitening. In this way, apparently surprising expressions of racism today can be better understood, in light of the inflections of racism itself as a socio-historical construction.
\end{abstract}

Keywords

Race; Racism; Inequality.

Artigo recebido: novembro de 2020

Artigo aprovado: dezembro de 2020 


\section{Introdução}

Neste artigo nossa atenção estará direcionada para discussão do racismo particularmente em relação ao negro, embora, nem por isso, desconsideremos que esse atingiu indígenas e outros grupos que não atendiam ao fenótipo branco europeu.

É importante destacar que o racismo molda as relações raciais e produz um sistema que estabelece a divisão das riquezas socialmente produzidas no mundo, tanto pela classe social de pertença dos sujeitos, como pela racialização dessas mesmas classes.

Nosso objetivo é uma aproximação da expressão singular do racismo no Brasil, concebido a nosso ver como racismo à brasileira, pois embora esteja relacionado as ideologias de supremacia racial disseminadas historicamente pelo globo, possui contornos específicos no Brasil. A partir desse objetivo, procuramos abordar a escravidão racial como parte da formação do racismo nacional, particularmente pela sua manipulação discursiva no sentido dessa ser retratada como "benigna" "suavizada" etc.

O racismo científico concebido no século XIX na Europa ganhou uma adaptação nacional, uma vez que em suas origens não poderia coadunar-se com a ideia de miscigenação para servir aos interesses de construção de um projeto nacional que via no negro o entrave a modernização do país;

Por fim, Freyre como síntese do processo iniciado com a escravidão em sua obra clássica Casa grande e senzala vai contribuir definitivamente para a noção democracia racial, a obra de Freyre sintetiza uma forma de pensar as relações raciais brasileiras, colocando, principalmente, o intercurso sexual inter-racial como símbolo da não existência de racismo enquanto sistema de privilégios e poder e critério de divisão de riquezas socialmente produzidas.

Esses três tópicos de análise guiaram a divisão do texto em três seções, a fim de torná-lo mais claro e objetivo. Por fım, optamos por construir uma breve subseção trazendo como os discursos que se erigiram no decorrer do tempo são utilizados até os dias atuais, inclusive 
no que diz respeito ao rechaço as políticas acionadas pelo Estado no sentido de enfrentar o racismo.

Gostaríamos de ressaltar que essa divisão não significa fragmentação e linearidade dos acontecimentos, pensamentos e discussões, até porque o texto pretende uma lógica dialética evidenciando rupturas e permanências na construção do racismo.

Ademais, nossa tarefa está situada na historicidade desses fenômenos, embora tenhamos muito claro que mudanças importantes ocorreram em outros períodos históricos, e que atualmente vivemos processos raciais com diferenças. Não podemos negar que muito da continuidade dessas relações, como bem apontado no dossiê temático do IPEA 2017 sobre título Democracia racial e homicídios de jovens negros na cidade partida, evidencia como está presente o mito da democracia racial, como mecanismo ainda hoje de encobrimento das iniquidades ensejadas pelo racismo.

Portanto, não foi nosso intento trazer as expressões contemporâneas do racismo na sociedade brasileira, mas rastrear os pontos em que se sedimenta os fundamentos dessas relações, procurando algumas de suas especificidades. Dentre elas, uma das mais fulcrais é a miscigenação e branqueamento que se articularam em torno da democracia racial e são postulados como chave de mobilidade social, porém as realidades dos dados concretos demonstram que pretos e pardos (miscigenados) encontram-se em profunda desigualdade frente ao grupo branco. O que desmistifica a ideia de branqueamento como ascensão social (OSORIO, 2004; PAIXÂO, 2017).

\section{Escravidão mercantil africana afro-brasileira: transformando negro em "peça"}

É importante iniciarmos situando o próprio "descobrimento do Brasil" na expansão ultramarina ${ }^{2}$, como parte de um movimento maior na busca de expansão da produção de matérias primas para abastecimento da manufatura mercantil (BORGES, MEDEIROS e D'ADESKY,2002). 
O trabalho escravizado foi sem dúvida fundamental para a consolidação do capitalismo, assim esse momento é central pois propiciou um nível de acumulação para a Europa até então sem precedentes, ao utilizar-se da mão de obra escravizada e usurpar a terra dos povos originários (CHIAVENATO, 2012; HONOR, 2015).

Ao mesmo tempo, o capitalismo se caracteriza por coisificar e mercantilizar as relações e os próprios indivíduos, pode-se perceber que a escravidão se relaciona analogamente a esse processo ao pretender tornar seres humanos como mercadorias, ou como denominado no período da própria escravidão, "peças" num processo que em última análise reduziria humanos a um instrumento de trabalho que poderia ser adquirido e comercializado (MOURA,1983; ANDREWS, 1998; CHIAVENATO, 2012.)

Os negros eram pesados e medidos. Eram "peças da África" [...] própria forma como se comercializavam os negros africanos era reflexo da sua desumanização: não se vendia um negro, dois negros, cinquenta negros - vendiam-se peças. (CHIAVENATO, 2012:102)

Mas chama atenção um fato evidente, por que a escravidão ganhou contornos fenotípicos? A questão é que do ponto de vista ideológico foi à reedição de um mito bíblico que justifıcou a escravidão, particularmente dos africanos, é no mito de Cam, o filho de Noé, que teria desonrado o pai que essa justificativa toma forma. A maldição seria de que Cam e seus descendentes deveriam ser escravos de seus outros irmãos Sem e Javé, ocorre que os canaanitas seriam os africanos, os semitas judeus e os descendentes de javé europeus (BORGES, MEDEIROS e D' ADESKY, 2002).

É importante colocar que mesmo antes da escravidão colonial, a demonização do continente africano, bem como o estabelecimento de negros como "semibestas", já ocorria e que o entendimento de que os africanos não possuíam alma também já existia, mas todos esses argumentos são utilizados no processo de escravização como meio 
para garantir o sequestro e a exploração do trabalho forçado de africanos, e depois de seus descendentes nascidos no Brasil (CHIAVENATO, 2012; BORGES, MEDEIROS e D' ADESKY, 2002; MAESTRI, 2017).

Soma-se a esses aspectos, a ideia disseminada que os africanos escravizados e seus descendentes tinham na condição de escravo o modo de purgar seus pecados, o modo de martirizar suas culpas por serem eles "incivilizados", "escravos de seus instintos" (BOSI, 1992, MAESTRI, 2017).

Por fim, o tráfico negreiro representou um empreendimento lucrativo que enriqueceu indivíduos e nações. No caso do Brasil, tanto no período colonial, como no pós-independência, é a coisifıcação do negro uma das formas mais rentáveis de lucro. Na esteira desse processo, ocorre a concentração fundiária e a formação de uma elite, a princípio colonial e mais tarde nacional, cuja escravidão se constitui como sua base (CHIAVENATO, 1987; ALMEIDA, 2015; BOSI, 1992; MOURA, 1983).

Cabe lembrar que o Brasil é o último país a abolir a escravidão e é fato que além dos próprios movimentos abolicionistas, rebeliões e quilombos havia uma pressão externa especialmente advinda da Inglaterra para o fim da escravidão, pois esse modelo já não era mais interessante para o capital central, que pretendia a expansão do mercado de consumo para seus produtos (ANDREWS, 1998; CHIAVENATO, 1987; HONOR, 2015). Constitui-se então a necessidade da figura do trabalhador assalariado para escoar sua produção, isso nos revela as determinantes impostas pelas relações do capital com a escravidão (ANDREWS, 1998).

A escravidão, por sua vez, traz no seu bojo o preconceito e a ideologia da inferioridade da população negra, a própria forma de divisão racial do trabalho na colônia irá construir o lugar reservado ao negro no Brasil (ALMEIDA, 2017).

Ao mesmo tempo, é na negação da escravidão como processo de construção sócio histórica no Brasil que repousa uma das primeiras singularidades da construção e expressão do nosso racismo. O apa- 
gamento da figura do escravizado como trabalhador que erigiu os alicerces da nação torna-se lugar comum (MOURA,1983).

Esse processo ocorre ora acionado pela romantização da escravidão, ora pela noção de algo que pertence a um passado remoto, e que não mais encontra ecos no presente, pois a própria concepção de divisão do trabalho na sociedade brasileira "bebe dessa fonte até hoje" (MOURA, 1983; ALMEIDA, 2017).

Mesmo a miscigenação como possibilidade de branqueamento já surge nesse período, vide a exaltação do mulato que aparece em obras como a de Andreoli, obviamente uma exaltação mais retórica do que concreta, e a situação dos pardos até hoje em nossa sociedade, mas que serviu a disseminação de uma ideologia de competição entre os pretos e pardos, a fim de, se aproximar do branco, símbolo máximo da detenção de poder e posse no período colonial (BOSI, 1992).

Esse modus operandi é extremamente eficiente quando pensamos que desde o período colonial a população negra brasileira circunda em torno de $50 \%$ da população, e as classes dominantes locais precisam de um aporte ideológico suficientemente forte, para fragmentar qualquer possibilidade de unidade nessa população que poderia de fato colocar em cheque a ordem vigente e não, por acaso, no pós abolição a miscigenação o branqueamento e a inferioridade racial, se tornaram cada vez mais propulsoras da construção da nação.

\section{Racismo científıco criando a raça marcando estereótipos}

Uma cena que pode ilustrar o racismo científico ${ }^{3}$ é a representação do negro nas telenovelas, quase que invariavelmente representado como pouco inteligente e "domesticado", ou criminoso e pouco amigável, podemos "agradecer" ao racismo científico a base fundamentada do racismo como uma verdade 4 . Isso ocorre porque desde a metade do século XIX, o racismo científico que postulava a supremacia racial branca, já se fazia presente entre os intelectuais nacionais. No entanto, além das ideias europeias de origem, nos 
interessa mais particularmente a apropriação do racismo científico no Brasil (SCHWARCZ, 1993).

No século XVII começou a ser esboçada a ideia de relacionar características físicas de um povo aos seus traços culturais e sociais, ou seja, foi a partir desse século que começaram as primeiras proposições sobre raça $a^{5}$ propriamente dita, ainda assim não eram explicações cientificas.

Ao mesmo tempo em que o humanismo inaugurou a concepção de uma unidade racial baseada no princípio de que há uma igualdade entre todos os seres humanos, fundamentada principalmente nas teorias de Rousseau, alguns teóricos naturalistas como Lineu ${ }^{6}$ e Buffon ${ }^{7}$, do mesmo período, começaram a classificar e hierarquizar os seres humanos baseando-se no princípio da supremacia europeia sobre os outros povos.

Em 1768, foi adicionada a esse corpus teórico a noção de degeneração, isso ocorreu nas publicações do jurista Cornelius de Pauw, que deu novos nuances a esse conceito, em princípio por aplicá-lo a seres humanos, e ao mesmo tempo por redefini-lo como um desvio patológico do modelo original (SCHWARCZ, 1993). Sua visão associou à patologia as diferenças existentes entre os seres humanos e em consonância com uma profunda estratificação a partir do pensamento europeu. Dentro da lógica desse autor, o tipo original era o europeu, e as demais “espécies” humanas eram tipos desviantes, enfraquecidos.

Ao olharmos para o século XVIII percebemos que o racismo permeava o pensamento científico, são essas as condições que fizeram consolidar as teorias raciais.

Com a publicação de A origem das espécies, em 1859, por Charles Darwin, mais alguns elementos foram trazidos para a conceituação do termo "raça"9. A obra de Darwin era biológica e estava calcada no conceito de adaptação das espécies como forma de garantir a sobrevivência mediante as transformações ocorridas na natureza.

O que ocorreu após o lançamento dessa obra foi à transposição da teoria darwinista para a realidade dos seres humanos, somou-se a 
isso uma distorção dos conceitos utilizados em sua pesquisa e a partir daí as ideias de seleção natural, competição entre outras passaram a servir de análise para os seres humanos inaugurando o "Darwinismo social"10. A partir desse momento, a teoria racial tomou um novo impulso, de tal maneira que todas as áreas de conhecimento foram influenciadas por esse tipo de interpretação (SCHWARCZ, 1993).

Firmaram-se a partir de então os postulados da teoria racial: as raças são distintas por princípio, e qualquer cruzamento entre elas levaria a degeneração" ${ }^{11}$, haveria uma correlação entre o fenótipo e os valores, a cultura e a sociabilidade de um povo. Por fim, a ideia de que o meio determina os indivíduos tornou-se tão dominante e que o termo raça se transformou em sinônimo de meio, logo o ser humano foi reduzido ao fruto de sua suposta raça.

A miscigenação a partir dessas teorias passou a ser considerada nociva para todas as "raças humanas", com o estabelecimento da relação entre degeneração e mistura configurando a concepção de impureza e bestialidade ${ }^{12}$.

A hierarquização baseada no conceito de raça cristalizou o princípio de supremacia de uma raça sobre as outras, conceituou o mestiço como a pior de todas as degenerações, já que isso levaria a uma raça débil (SCHWARCZ, 1993). Esse foi o trajeto tomado pela categoria raça a partir de sua conceituação cientifica.

No caso brasileiro, os pensadores recriaram essas teorias de modo que elas coubessem nos interesses do projeto de identidade nacional (SCHWARCZ, 1993). Nesse sentido, é possível apreender que desde a independência do Brasil foi sendo desenhado um projeto de branqueamento $^{13}$, e no segundo império essa concepção tomou força e tornou-se um arcabouço teórico.

O Conde Coubineau, amigo e conselheiro de Dom Pedro II, que viveu no Brasil durante o ano de 1869, declarava a inferioridade racial negra e à degeneração que seria levada a termo com a mistura das raças no Brasil (CHIAVENATO, 2012; NASCIMENTO, 2017). 
No transcorrer do século XIX esse pensamento se torna hegemônico, em tal medida, que mesmo a campanha abolicionista sofreu a influência dessa ideologia ${ }^{24}$. Isso porque a abolição começou a ser vista como a possibilidade de libertar o Brasil dos negros, agora culpados pelo atraso da nação. Tal questão foi denominada de "problema do negro".

Entre 1888 e 1890, a soma de negros e mulatos ${ }^{15}$ perfaziam mais de $55 \%$ da população brasileira isso significa que mais da metade da nação era considerada inferior e potencialmente perigosa (CHIAVENATO, 2012; NASCIMENTO, 2017). E convém lembrar, que a luta em torno da abolição havia demonstrado às elites o potencial de organização e combate de escravizados e classes populares. Assim, a assimilação do racismo científico foi a resposta encontrada para resolver o "problema do negro" (ANDREWS,1998).

A ideologia do branqueamento tem solo cada vez mais fértil e se consolida a partir de variados aspectos de ordem racial, política, econômica e social, dentre os quais destacamos: o mito da inferioridade racial do negro, a política de imigração europeia, a exclusão do negro do mercado formal de trabalho e sua associação à vadiagem, e por fım, mas não menos importante, a miscigenação como fator que conduziria o Brasil a uma nação branca, onde os traços africanos seriam eliminados (NASCIMENTO, 2017).

Silvio Romero, da Faculdade de Direito de Recife relata que:

[...] A vitória na luta pela vida, entre nós, pertencerá no porvir, ao branco; mas que esse, para essa mesma vitória atenta às agruras do clima, tem necessidade de aproveitar-se do que de útil as outras duas raças lhe podem fornecer, máxime a preta, com quem tem mais cruzado, pela seleção natural, todavia, depois de prestado o auxílio de que necessita, o tipo branco irá tomando a preponderância até mostrar-se puro e belo como no velho mundo (ROMERO, 1980:924 apud CHIAVENATO, 2012:156).

A partir desse trecho podemos perceber as influências do evolucionismo, do Darwinismo social e da miscigenação como forma de aprimo- 
ramento genético, ao mesmo tempo em que são traçadas as ações que deveriam ser tomadas no sentido de garantir a melhoria racial pretendida.

Francisco José Oliveira Viana, do Instituto Histórico e Geográfico Brasileiro-IHGB, em 1920 escreveu o relatório "histórico" Evolução do Povo Brasileiro, o texto introdutório do censo de 1920, em um de seus trechos dizia:

Neste trabalho de aryanização do nosso povo, há outros collaboradores mais enérgicos do que a immigração das raças brancas da Europa. Há seleções naturaes e sociaes, que aceleram extraordinariamente entre nós a rapidez do processo reductor dos elementos etnicamente inferiores. (RECENSEAMENTO do BRAZIL, 1920 apud REGUEIRA, 2004: 35).

Nas palavras de Hasenbalg,

A miscigenação aponta para a homogeneidade e inclusão e se contrapõe às normas de separação e pureza vigentes em outros sistemas raciais. Mas a mistura racial é também um passo no caminho ao branqueamento, resultado final esperado, que implicaria hierarquia e valorização negativa de negros e índios. (HASENBALG, 1996 apud REGUEIRA, 2004:33)

Por sua vez, a imigração é acionada como parte da estratégia do branqueamento orientada pelo racismo científico, a questão do desenvolvimento nacional fica resolvida pela "marcha rumo a branquitude". Podemos dizer que essa marcha tinha o mesmo significado da "marcha do progresso", porque progredir significava antes de tudo fazer desaparecer o negro como parte da nação.

Esse quadro vai construindo progressivamente tonos específicos para o racismo, a saber:

i) Ao invés, de investir diretamente em leis segregacionistas, ou acionar outras formas "legais" de apartheid, produz e dissemina: o "negro" como aquele que por princípio deve entender o branco como melhor e deve querer tornar-se esse, mesmo que para ele isso não seja possível; 
ii) O filho do intercurso interracial estaria mais próximo desse ideário e gozaria de uma vida melhor, o que não se confirmou vide os dados de acesso a direitos sociais básicos como educação, saúde, trabalho etc. Confirmados exaustivamente pelos estudos de: Paixão, 2017; Nascimento, 2017; Chiavenato, 2012. E ainda, a partir da divulgação de dados da PNAD $^{16}$ do terceiro trimestre de 2017, pretos e pardos perfaziam o maior número de desempregados e de trabalhadores informais tanto em números absolutos, quanto quando proporcionalmente comparados aos brancos, provando que mesmo nos dias atuais a proclamada mobilidade via miscigenação é muito mais estratégica para a divisão interna do grupo populacional identificado como negro, do que um dado concreto de mudança social (NEDER e NUNES, 2017);

iii) Embora até a abolição os negros ${ }^{17}$ fossem força massiva de trabalho, no pós-abolição, ocorre sua identificação como vadio, numa espécie de ciclo que basicamente tinha haver com a ideia bastante calcificada de que o negro apenas trabalhava em face da utilização da força, uma vez que eram avessos ao trabalho;

iv) E por fim, o processo de interiorização entre a própria população negra desses estigmas e estereótipos de modo a consolidar uma busca de um modelo de futuro (branco) em que se apaga a história (negra).

\section{A mestiçagem/miscigenação em Freyre e a construção do mito da igualdade racial}

Em 1933, Freyre lança Casa Grande e Senzala, que trouxe em seu bojo uma nova forma de discutir a questão racial. A obra de Freyre centra-se na formação social brasileira, seu maior feito provavelmente foi colocar as três raças como construtoras da sociedade brasileira (não sem as hierarquizar), afırmando que cada uma delas contribui com sua cultura para a construção da nação, e nos seus trabalhos posteriores continuou a desenvolver tais teorias (FREYRE, 1998). 
Outro mérito da obra é a retomada histórica do Brasil procurando ressignificar os aspectos antes tidos como depreciativos da nação brasileira. É uma revalorização da nacionalidade procurando exaltar as características nacionais, principalmente a ideia de um país em que as raças conviviam de modo harmonioso, e que diferente dos Estados Unidos, não existia um violento conflito racial.

Contudo a obra de Freyre está centrada no elogio ao mestiço - e a mestiçagem como estratégia - este seria o representante da nação por excelência, é ele o grande símbolo da democracia racial. É a fusão das três raças tanto em nível cultural quanto biológico que deu ao Brasil a sua nacionalidade. A questão é que mais uma vez tratou-se de uma "armadilha", porque recai sobre a tese da miscigenação como resolução da questão racial nacional e da questão do progresso nacional.

Ainda que de maneira diferenciada das teorias racistas adaptadas à realidade brasileira, Freyre também colocou a miscigenação como resolução da questão racial no Brasil. É como se ao criar a figura do mestiço o Brasil naturalmente resolvesse seu problema racial, pois as barreiras raciais não seriam rígidas no Brasil, e uma convivência harmônica se estabeleceria. De certo modo não deixa de ser uma solução biológica, pois é o intercurso físico que cria o tipo brasileiro (SISS, 2003).

Assim como ocorre a miscigenação racial, ocorre para Freyre (1998) a mistura cultural; o sincretismo cultural compõe a nacionalidade. As culturas se imbricaram de tal maneira que esse cruzamento em si é a cultura nacional, mas ao fazer essa colocação o autor, novamente, coloca a questão racial como algo solucionado, pois, reconhece a participação das três culturas fundantes do Brasil e consoante diz que elas se fundiram para formar a cultura brasileira.

Assim a discussão Freyriana fez à proposição do intercurso sexual entre senhores de escravos e mulheres negras escravizadas como símbolo da não existência de racismo (no sentido de aversão) aqueles considerados negros. 
A questão que parece ficar fora da discussão tem relação com qual o lugar reservado a mulher negra nessa narrativa e que ao final a miscigenação tem um curso e esse curso é o branqueamento dos brasileiros.

Outro ponto nevrálgico parece estar localizado no que tange a escravidão, é o nível de autonomia de uma pessoa escravizada sobre seu corpo e qual a possibilidade de consentimento para esse tipo de relação que por definição já era completamente assimétrica (SILVA, 2006).

Ainda é preciso considerar a "confusão" entre intercurso sexual e ausência de preconceito, Stolke (2006) citando Bastide, vai dizer que "sexo" sem casamento na ordem societária tanto no período escravocrata quanto no momento em que Freyre está escrevendo significa apenas o uso e abuso do corpo feminino, que não possuía nenhuma legitimidade para exigir nada.

Logo, essa mulher tornada escrava (e mesmo aquelas libertas), não é mais que um instrumento da satisfação desse homem branco europeu detentor de posse, obviamente houve exceções, mas elas não mudam o modo de organização vigente e as profundas marcas que este deixou (SILVA, 2006).

Nesse sentido, a própria masculinidade desse homem é reificada através do abuso do corpo da mulher negra; é como se ao final fosse um atestado dessa masculinidade, por outro lado esse corpo é como o hospedeiro necessário a gênese de um novo ser - o "mulato" que é ao final o representante da nação (SILVA, 2006).

Quanto ao "mulato", “mestiço”, “pardo”, “moreninho”, dentre outros, seria segundo o pensamento de Freyre (1998), o que com o tempo iria tornar-se o branco dos trópicos tanto pelos próprios processos de miscigenação que tornariam a população cada vez mais branca, como pela sua busca pelo status da branquitude.

A despeito de ser um marco de reação às teorias biológicas de cunho racista, a perspectiva teórica de Freyre é sistematizadora do ideário da democracia racial, um modo de pensar que se instalou no imaginário nacional e que invisibiliza as desigualdades sócio raciais. 


\section{Um museu de grandes novidades ${ }^{18}$ : o velho/novo racismo}

Como já dito anteriormente, mesmo antes da abolição já se desenhava o "problema do negro", que para as nossas elites significava a composição racial brasileira como o grande obstáculo ao progresso nacional.

Tendo como direcionamento os valores civilizatórios europeus e a compreensão de progresso, completamente desarticulada de um mínimo de investimento em ações do Estado que visasse educação, regulação do trabalho entre outras medidas. Passamos a uma discussão de desenvolvimento nacional que articulava de maneira imediata supostas características raciais a progresso e desenvolvimento. Isso contribui para explicar por que a discussão racial tomou larga dimensão, e o Estado construiu políticas de investimento na imigração como solução do "problema negro" e ao mesmo tempo do progresso (CARVALHO, 2002; ANDREWS,1998).

E por fim, a democracia racial de muitos modos substituiu a discussão da democracia política é como se pudesse ocorrer uma transposição, se existisse uma democracia racial existiria uma democracia política, talvez não seja admirável que a síntese dessa ideia se dê em meio a um período de suspensão dos diretos políticos no período Vargas (HANCHARD, 2001).

A propósito, a concepção de democracia racial esteve balizada pelo fato de existir miscigenação racial, daí conclui-se que é esse um empecilho natural ao racismo. De certo modo, assim como a democracia política foi vivida de modo quase esporádico ao longo da história brasileira, a democracia racial não passou de uma possível utopia baseada em algumas exceções que mais confırmaram a regra das injustiças calcadas no racismo.

Mas não podemos deixar de considerar um fato marcante, o poder material de uma ideologia de tal modo que com a implementação das Ações Afirmativas e principalmente com o advento das cotas raciais, faz ressurgir os argumentos calcados na democracia racial e na antiga tese da inexistência do racismo no Brasil, de modo que temos um livro 
lançado por um alto executivo das organizações globo, Sr. Ali Kamel chamado Nós não somos racistas: uma reação aos que querem nos transformar numa nação bicolor, em 2006. Uma coletânea realizada por pesquisadores de renome no Brasil (alguns inclusive que construíram suas carreiras discutindo o racismo), Dr. Peter Fry, Dr ${ }^{a}$ Yvone Maggie, Dr. Marcos Chor Maio, Dra Simone Monteiro, intitulado Divisões Perigosas, em 2007, cuja base argumentativa são a reedição deste arcabouço teórico ideológico (COSTA, 2011).

A persistência e acionamento dessas expressões do racismo demonstram a sobrevida da ideação democracia racial, e a correlata inexistência do racismo e mostram que essas não são questões do passado, ao contrário elas se fazem presentes no cotidiano brasileiro, de tal forma que em estudo realizado por Camino e colaboradores, em 2014, sobre as políticas de ação afırmativa e mais especificamente sobre cotas raciais, um dos argumentos mais utilizados pelos estudantes contrários as cotas se referia ao enunciado de igualdade entre negros e brancos, uma igualdade marcada pelo formalismo abstrato da democracia racial que desconsidera o conjunto de desigualdades enfrentadas por essa população.

\section{Considerações finais}

Esse breve passeio pela construção sócio-histórica dos conceitos/ ideias de raça, racismo, miscigenação, nos mostra a maneira como raça tem sido acionada como mecanismo de exploração, privilegiamento e estabelecimento de poder e aquisição da posse, inclusive sobre o outro, infelizmente estamos longe de superarmos do ponto de vista social, aquilo que a biologia ultrapassou; a separação dos seres humanos através de critérios fenotípicos.

O racismo é um sistema que ultrapassa as fronteiras nacionais, tanto que, entre metade do século $X X$ e início do $X X I$, ocorreram três conferencias internacionais para tratar desse tema, contudo o modo como ele se desenvolveu no Brasil é marcado por alguns aspectos específıcos, a miscigenação apreendida como valor símbolo da unidade 
nacional, a construção de um imaginário coletivo que inferioriza mais da metade da população brasileira e o obscurecimento do trabalho de africanos e seus descendentes escravizados.

Soma-se a esses aspectos o encobrimento do questionamento acerca da fundação da riqueza das elites nacionais nos braços de cativos, assim como a exclusão do negro no mercado formal de trabalho uma vez que no pós-abolição se instaurou uma hierarquização racial que permaneceu relegando aos negros as formas de trabalho mais aviltantes, humilhantes e degradantes.

Podemos dizer que ao longo do tempo ocorreram avanços. Eles têm se intensificado nos últimos 20 anos, ainda assim alguns fenômenos demonstram não só a persistência, mas a necessidade de um combate antirracista, a saber, o crescimento dos partidos de extrema direita na Europa à onda conservadora e reacionária que vem atingindo o Brasil, o assassinato diário de jovens negros moradores da periferia, os persistentes índices de desigualdade entre negros e brancos no Brasil e poderíamos certamente sinalizar no mundo. Isso mostra que o racismo enquanto sistema é um dos princípios que hierarquiza as vidas humanas em todas as suas dimensões, nesse sentido faz-se necessário enfrentá-lo não só a partir de suas expressões mais individualizadas, mas como parte da estrutura social ou, antes, como uma máquina que leva destruição e espalha a morte, enquanto constrói um abismo de desigualdade entre seres humanos.

\section{Referências}

ALMEIDA, Magali da Silva. Desumanização da população negra: genocídio como princípio tácito do capitalismo. Revista Em Pauta, v. 12, n. 34, 2015. Acessado em 15/09/2017, disponível em: http://www.e-publicacoes.uerj.br/ index.php/revistaempauta/article/view/15086 Acesso: 10/11/2017

ALMEIDA, Silvio Luiz de. Estado Direito e Análise materialista do racismo. Disponível em: https://grupodeestudosracismoecapitalismo.files.wordpress. com/2017/05/silvio-de-almeida-estado-direito-e-anc3a1lise-materialista-do-racismo.pdf. Acesso em: 10/11/2017. 
ANDREWS, George Reid. Negros e brancos em São Paulo (1888-1988). São Paulo: EDUSC, 1998.

BORGES, E.; MEDEIROS, C. A.; D’ADESKY, J. Racismo, preconceito e intolerância. São Paulo: Atual, 2002 - (Espaço \& debate).

BOSI, Alfredo. Dialética da colonização. São Paulo: Companhia das letras, 1992. Acesso em: 15/09/2017 disponível em: http://www.iphi.org.br/sites/filosofia_brasil/Alfredo_Bosi__Dial\%E9tica_da_Coloniza\%E7\%E3o.pdf

CAMINO, Leoncio et al. Repertórios discursivos de estudantes universitários sobre cotas raciais nas universidades públicas brasileiras. Psicologia \& Sociedade, v. 26, 2014.

CARVALHO, J. M. Cidadania no Brasil: o longo caminho. 3ed. Rio de Janeiro: Civilização Brasileira, 2002

CERQUEIRA, Daniel; COELHO, Danilo Santa Cruz. Democracia racial e homicídios de jovens negros na cidade partida. 2017. Disponivel em: https://scholar.google.com.br/scholar?hl=ptBR\&as_sdt=0\%2C5\&q=Democracia+Racial + e+Homic\%C3\%ADdios+de+Jovens+Negros+na+Cidade+Partida\&btnG $=$ Acesso em: 10/11/2017.

CHIAVENATO, Julio José. O negro no Brasil. São Paulo: Ed. Cortez,2012.

COSTA, Ricardo Cesar Rocha da. O pensamento social brasileiro e a questão racial: da ideologia do "branqueamento" às "divisões perigosas". In: Relações étnicorraciais na escola: desafios teóricos e práticas pedagógicas após a Lei 10.639, p. 28, 2011.

DAMASCENO, Janaína. O corpo do outro. Construções raciais e imagens de controle do corpo feminino negro: O caso da Vênus Hotentote. In: Fazendo Gênero 8 Corpo, violência e poder. ST 69 - Pensamento negro, corporeidade e gênero: textualidades acadêmicas, literárias e ativistas. Florianópolis: 2008. Disponível em: http://www.fazendogenero.ufsc.br/8/sts/ST69/Janaina_Damasceno_69.pdf. Acessado em: 10/08/2014

FREYRE, Gilberto. Casa Grande \& Senzala. Rio de Janeiro/São Paulo: Record, 1998. HANCHARD, M. G. Orfeu e o poder: movimento negro no Rio de Janeiro e São Paulo (1945-1988). Rio de Janeiro: EDUERJ, 2001.

HONOR, André Cabral. A base do conceito de escravidão na historiografia brasileira: Eric Williams e sua obra seminal capitalismo e escravidão. Fenix - Revista de História e Estudos Culturais. Brasília, Vol 12, Ano XII, n 1, 2015. 
MAESTRI, Mário. Zurara: A Crônica da Guiné e os Primórdios do Racismo Anti-Negro. In: Academia.edu. https://www.academia.edu/11669765/ . Acesso em: 10 /11/2017.

MOURA, Clóvis. Escravismo, colonialismo, imperialismo e racismo. Afro-Ásia, n. 14, 1983. Acesso em: 15/09/2017, disponível em: https://scholar.google.com. $\mathrm{br} / \mathrm{scholar} ? \mathrm{hl}=\mathrm{ptBR} \& a s_{-} \mathrm{sdt}=0 \% 2 \mathrm{C} 5 \& \mathrm{q}=\mathrm{ESCRAVISMO} \% 2 \mathrm{C}+\mathrm{COLONIALIS}-$ $\mathrm{MO} \% 2 \mathrm{C}+$ IMPERIALISMO+E+RACISMO\&btnG=

NASCIMENTO, Abdias. O genocídio do negro brasileiro: processo de um racismo mascarado. Editora Perspectiva SA, 2017.

NEDER, Vinicius, NUNES, Fernanda. Seis em cada dez desempregados são pretos ou pardos, diz IBCE. O Estado de São Paulo. São Paulo, 17 de novembro de 2017. Economia \& Negócios. Disponível em: http://economia.estadao. com.br/noticias/geral, pretos-e-pardos-ganham-metade-do-que-os-brancos-diz-pnad,70002088126. Acesso em: 18/11/2017.

OSORIO, Rafael Guerreiro. O sistema classificatório de "cor ou raça” do IBCE. In: BERNARDINO, Joaze e GALDINO, Daniela (org.). Levando a raça a sério: ação afirmativa e universidade. Rio de janeiro: ed. DP\&A,2004. p 85 - 137. (coleção políticas da cor)

PAIXÃO et.all. Relatório Anual das Desigualdades Raciais no Brasil (20092010). Editora Garamond.S/D. Disponível em: http://www.palmares.gov. br/wp-content/uploads/2011/09/desigualdades_raciais_2009-2010.pdf .Acesso em: 30/03/2017.

RECUEIRA, Aparecida Tereza Rodrigues. As informações estatísticas em relações raciais e a natureza da investigação do quesito cor nas pesquisas sobre a população no Brasil: contribuição para o estudo das desigualdades raciais na educação. Dissertação (Mestrado em Educação) - Rio de Janeiro: UERJ, 2004.

SCHWARCZ, L. K. M. O Espetáculo das Raças. Cientistas, Instituições e Pensamento Racial No Brasil: 1870-1930. São Paulo: Companhia das Letras, 1993. SILVA, Denise Ferreira da. À brasileira: racialidade e a escrita de um desejo destrutivo. Rev. Estud. Fem, Florianópolis, v. 14, n. 1, Abril. 2006.

SISS, Ahyas. Afro-brasileiros, cotas e ação afirmativas: razões históricas. Rio de Janeiro: Quartet, 2003.

STOLKE, Verena. O enigma das intersecções classe, raça, sexo, sexualidade: a formação dos impérios transatlânticos do século XVI ao XIX. Revista Estudos Feministas. Florianópolis, 14(1), janeiro-abril/2006. 


\section{Notas}

1 Assistente Social (Angra dos Reis) Brasil; Mestre em Saúde Coletiva IFF/FIOCRUZ; Doutorando em Serviço Social FSS/UFRJ; ORCID: https://orcid.org/0000-00018326-3110; joutromundo2000@gmail.com

2 Desde o final da Idade Média europeia (1350-1450), a história vem registrando a unifıcação do mundo pelo capitalismo: a gradativa constituição do mercado internacional, envolvendo economia, política e cultura, a partir de um movimento comumente designado nos manuais de história como - expansão ultramarina, comercial e colonial europeia (BORGES, MEDEIROS e D’ ADESKY, 2002:11).

3 Neste texto escolhemos não denominar pseudo-científico, ou por aspas, uma vez que de fato corpos negros foram abusados para a construção de supostas verdades científicas e mais, subsidiaram conhecimentos que foram incorporados à própria ciência. Vide o caso de Saartjie Baartman, mulher africana que além de uma história marcada pela violência das mais diversas formas, teve ao final, seu corpo vendido para Georges Cuvier, que a teve como objeto de seus estudos e formulações e, sobre seu corpo, solidificou sua carreira cientifica tornando-o até hoje reverenciado (DAMASCENO, 2008).

4 Devemos lembrar que uma das questões mais caras à ciência principalmente nesse período é o estabelecimento da verdade, portanto o racismo como prática já existia, mas ganha novo estatuto a partir dos pressupostos científicos, logo os estereótipos ganham lugar de uma imagem fixa, uma prisão.

5 "O viajante francês François Bernier foi um dos primeiros a adotar critérios como cor da pele e outras características somáticas para dividir o gênero humano em quatro ou cinco espécies ou raças humanas (..) Bernier não hesitava em usar termos depreciativos; segundo ele, os asiáticos tinham - olhinhos de porco-, os negros, em vez de cabelos tinham - uma espécie de lã parecida com o pelo das nossas lontras -, e os lapões eram - feios como animais. Evidentemente, os europeus eram poupados dessas comparações nada lisonjeiras" (BORGES, MEDEIROS e D'ADESKY, 2002:14). A publicação do artigo desse viajante, em 1684, não pode ser considerada um trabalho científico, mas demonstra como esse pensamento foi se construindo na história até se tornar uma teoria cientifica.

6 "O Sueco Lineu, por exemplo, em sua obra Systema Naturae, dividia o gênero homo (...) distribuíam-se em quatro grupos: o homem europeu (europaeus albus) - engenhoso, inventivo, branco, sanguíneo, governado pelas leis; o homem americano (americanus rubescus) - satisfeito com sua condição, gostando da liberdade, pardo irascível, governado pelos costumes; o homem asiático (asiaticus luridus) - avarento, amarelo, melancólico, governado pela opinião - e o homem africano (afer niger) - manhoso, preguiçoso, negligente, negro, fleumático, governado pela vontade arbitrária de seus amos. (BORGES, MEDEIROS e D’ADESKY, 2002:15). 
7 Buffon era um naturalista francês que em 1734 publica a infantilidade do continente, obra que explicita toda sua concepção eurocêntrica e delineando o contorno da superioridade do europeu frente aos outros povos (SCHWARCZ, 1993).

8 "Até então chamavam-se degeneradas espécies consideradas inferiores, porque menos complexos em sua conformação orgânica". (SCHWARCZ, 1993).

9 "O termo raça é introduzido na literatura mais especializada em inícios do século XIX, por Georges Cuvier, inaugurando a ideia da existência de heranças físicas permanentes entre os vários grupos humanos" (STOCKING, 1968:29 apud SCHWARCZ, 1993:47).

10 O Darwinismo social era um determinismo racial, que pressupôs a ideia de que as características eram inatas às raças humanas "as raças constituiriam fenômenos finais, resultados imutáveis" (SCHWARCZ, 1993).

11 Nota-se a integração do conceito de degeneração, lançada por Pauw, na teoria das raças.

12 "Para os autores Darwinistas sociais, o progresso estaria restrito às sociedades puras, livres de um processo de miscigenação[...]" (SCHWARCZ, 1993).

13 Em 1823, o então ministro das relações exteriores José Bonifácio expressou em uma carta, destinada ao cônsul inglês lorde Chamberlain, qual o tipo racial que deveria formar a nação brasileira: "Bonifácio disse a Chamberlain que gostaria que os ingleses capturassem todo navio negreiro (...) - não quero vê-los nunca mais, são a gangrena da nossa prosperidade, a população que queremos é branca (LUZ, 2000:217 apud CHIAVENATO, 2012:183).

14 "Em O abolicionista, Joaquim Nabuco tem o cuidado de explicar o que se pretende ao abolir a escravidão: - absorver o sangue caucásico vivaz, enérgico e sadio - que certamente embranqueceria o nosso povo" (CHIAVENATO, 2012:156)

15 Negro e mulato eram categorias censitárias à época, o que hoje equivaleria a pretos e pardos.

16 Pesquisa Nacional de Amostra Domiciliar (PNAD).

17 Aqui compreendidos como pretos e pardos.

18 Referência a trecho da música O tempo não para de autoria de cazuza. 